\title{
OS BENS SOCIAIS SÃO SEMPRE BENS CONVERGENTES?
}

\author{
Inácio Helfer ${ }^{1}$
}

RESUMO: Uma interpretação corrente do fenômeno social ensina que todos os bens coletivos são bens convergentes. As concepçôes bem-estarista e utilitarista na economia e na filosofia, respectivamente, são os seus principais expoentes. A tese consiste em aceitar que "totalidades sociais" são inexoravelmente compostas de "partes" e que, por isso, na base de cada bem público ou social se encontrariam sempre os indivíduos, os quais seriam, em última análise, responsáveis pela sua existência. Assim, os bens públicos seriam bens para os quais convergem interesses e escolhas dos agentes sociais. O presente estudo mostra, em primeiro lugar, segundo a compreensão de Taylor, que nem todos os bens coletivos são bens convergentes. Alguns bens sociais podem ser considerados bens irredutivelmente sociais, cuja justificativa se encontra na reflexão sobre o significado. Em segundo lugar, aborda a contribuição que a noção hegeliana de eticidade teve sobre a formulação desse argumento.

PALAVRAS-CHAVE: Bens sociais convergentes. Bens irredutivelmente sociais. Teoria da açáo. Taylor. Hegel.

Nos traços da reflexão sobre as possibilidades de uma sociedade democrática, que pretenda a estabilidade e a unidade de suas instituiçóes, o tema da identidade (política, cultural, nacional etc.) é destaque no discurso filosófico da modernidade. Taylor se interessa por esse assunto, sobretudo nas variantes da identidade cultural e da política do reconhecimento. Basicamente, sugere que, para entender as condições e as possibilidades de esclarecimento da noção de identidade, é necessário examinar as bases do agir humano. Por isso, propóe como tema central de debate saber sob que condiçóes se dá a sociabilidade humana, se ela pode ser explicada como embasada num forte sentido da identidade coletiva, ou num sentido fraco da mesma, como resultante de meros interesses particulares.

${ }^{1}$ Doutor em Filosofia pela Université de Paris I, Panthéon-Sorbonne. Professor e pesquisador em Filosofia na UNISINOS e UNISC. Email: inahelfer@gmail.com 
Para Taylor, a resposta a essa questão define campos de compreensão muito importantes, cujas práticas e influências sociopolíticas são de extrema atualidade. Embora não seja objeto deste estudo, cabe brevemente assinalar que elas podem se apresentar sob duas formas. Se se confirma a hipótese de que a identidade coletiva é um mero instrumento para a afirmação de valores individuais, entâo, com maior facilidade se sustenta o argumento de que a estabilidade e a unidade das instituiçóes democráticas têm a sua garantia num modelo liberal democrático de primazia dos direitos individuais, no sentido da valorização da acepção do justo em detrimento de valores coletivos. Se, ao contrário, se confirma que a identidade coletiva se mostra como um modo privilegiado das práticas humanas, o argumento de que a estabilidade e a unidade das instituiçôes democráticas tenha a sua garantia num modelo liberal democrático de primazia dos direitos coletivos possui uma força argumentativa maior do que a posição contrária. ${ }^{2}$ Expor a discussão em torno dessas questôes e explicar como é possível derivar implicaçóes práticas se encontra na base do debate entre liberais e comunitaristas, no qual Taylor tem participação. ${ }^{3}$

O objetivo do presente estudo é analisar argumentos que tornam aceitável uma ou outra acepção; não é, em primeiro lugar, o de examinar as implicaçóes práticas éticas e sociais de cada uma. Para alcançar essa meta, expõe e examina a argumentação de Charles Taylor sobre a capacidade humana de agir, sobretudo em torno de sua tese de que "[...] toda a ação não é em última análise efetuada por indivíduos; há açóes irredutivelmente coletivas.” ${ }^{\circledR} \mathrm{A}$ meta consiste em expor como tal descrição se estrutura e confirma a possibilidade de o homem querer e erigir bens irredutivelmente sociais, em especial no estudo intitulado "Bens irredutivelmente sociais". 5 Através dessa leitura se

\footnotetext{
2 As éticas liberais priorizam a questão do justo, no sentido de saber o que se deve fazer (a noção de obrigação) e desacreditam a questão do que é bom ser (realização de si na vida boa).

3 Para um estudo introdutório sobre o debate, ver a obra de BERTEN, A.; Da SILVEIRA, P.; POURTOIS, H. (Org.). Libéraux et communautariens. Paris: PUF, 1997. Para um estudo mais especializado, ver os textos dos comunitaristas Alasdair MacIntyre, Michael Sandel e Michael Walzer e Charles Taylor, e dos liberais John Rawls, Ronald Dworkin, Thomas Nagel e T. M. Scanlon.
}

${ }^{4}$ TAYLOR, C. Esprit et action dans la philosophie de Hegel. In: La liberté des modernes. Edição, tradução e apresentação de Philippe de Lara. Paris: PUF, 1997, p. 109.

5 Uma primeira ediçáo deste trabalho se encontra no capítulo intitulado "Irreducibly Social Goods", do livro de Geoffrey Brennan e Clif Walsh (Ed.). Rationality, Individualism and Public Policy. Canberra: Centre for Research on Federal Financial Relations, Australian National University, 1990. Em seguida, apareceu na coletânea de textos de Taylor, intitulada Philosophical arguments. Cambridge, Mass.: Harvard University Press, 1995, cuja traduçáo para o português foi realizada pela editora Loyola, em 2000. O presente artigo utiliza como fonte a edição brasileira: TAYLOR, C. Bens irredutivelmente sociais. In: Argumentos filosóficos. Trad. de Adail Ubirajara Sobral. São Paulo: Loyola, 2000c, 143-161. 
poderia entender com maior clareza como o homem é capaz de escolhas que vão além da mera afirmação de bens sociais convergentes, que, supostamente, garantiriam a estabilidade e a unidade das instituiçôes. Em consórcio com esse tema, constitui outro objetivo do estudo examinar em que medida tal leitura encontra raízes na filosofia hegeliana da noção de "eticidade". O texto acima não faz referências às contribuiçôes da filosofia de Hegel. No entanto, o que se sugere, e ao mesmo tempo é afirmado em alguns estudos de Taylor ${ }^{6}$, é que a emblemática cartografia da identidade moderna recebeu uma forte influência da noção hegeliana de um espaço comum compartilhado anterior a toda formação humana de valoração, que resulta, em parte, das ações dos indivíduos, mas que é também independente deles e, nessa condição, acaba por influir sobre a ação dos agentes. Com efeito, através desse dispositivo, ambos os argumentos se complementariam no sentido de revelarem uma posição favorável à estabilidade e à unidade das instituiçóes democráticas radicados na garantia de um modelo liberal democrático de primazia dos direitos coletivos, para a valorização de uma comunidade de valores compartilhados por uma sociedade. Avaliar como se dá a interação desses argumentos constitui, também, um escopo deste trabalho.

No geral, a leitura de Taylor sobre a pergunta inicial reforça o ponto de vista de que não se trata de começar pelo exame se o homem, de um modo abstrato ou hipotético (como é o caso para Hobbes), é ou não um ser social, para, em seguida, examinar as consequências derivadas desses pressupostos. O melhor percurso consistiria em examinar o modo peculiar concreto do agir humano, cujas evidências mostrariam a perspectiva mais contundente. Expressốes de sociabilidade são um dado factual empírico da vida humana, a partir do qual se pode examinar e formular conhecimento. Não se trata, por isso, de saber se o homem é um ser social por natureza. Trata-se de examinar no agir humano sinalizações que auxiliam a confirmar uma ou outra hipótese. A partir delas se poderia refletir sobre a ação, se ela é mais bem descrita à luz de uma perspectiva coletivista ou individualista.

Assim, como explicar as manifestações societárias nos homens? Os homens se associam em vista de fins que são verdadeiramente coletivos? $\mathrm{Ou}$ a sociabilidade nos homens ocorre apenas porque os mesmos se impóem a si certos padróes sociais em vista de fins particulares, sem os quais estes últimos

\footnotetext{
${ }^{6}$ Sobretudo nas produções Hegel, 1975 (Cambridge: Cambridge University Press), Hegel and Modern Society, 1979 (Cambridge: Cambridge University Press) e Hegel's Philosophy of Mind, 1985 (Human Agency and Language. Philosophical Papers I. Cambridge: Cambridge University Press, p. 77-94).
} 
não seriam alcançáveis? Neste caso, as expressôes de sociabilidade, a rigor, não seriam espontâneas, mas artificialmente impostas. Elas seriam apenas um meio para que os homens alcancem os fins individuais. Os homens as consentiriam em virtude dos benefícios que adquirem, pois se poderia supor que jamais os alcançariam no isolamento. A sinergia que a convivência social promove, por exemplo, a que resulta das interaçôes sociais no ambiente do trabalho, seria muito mais vantajosa para a consecução dos fins humanos do que a de uma situação contrária. Dessa forma, os homens interagiriam socialmente sabendo que, com essa prática, limitam certos planos de realizaçóes sob um aspecto, mas realizam outros de uma forma distinta, os quais seriam mais vantajosos.

Afinal, quando o homem se associa com outros ele o faz em vista de fins que podem ser considerados fins coletivos, no sentido forte da palavra? Quando o homem se associa com outros, ele certamente o faz em vista de fins, algo que para ele constitui um bem. Veja-se um exemplo banal. Se alguém aprecia tocar um instrumento musical, percussão, por exemplo, e considera que os sons que é capaz de produzir em conjunto com outros músicos alcança uma dimensáo mais satisfatória daquela que resulta da prática isolada do seu instrumento, como é ilustrado pela música produzida por uma banda de rock, e se todos os participantes da banda compartilham o mesmo ponto de vista, então se poderia afirmar que a banda constitui um bem coletivo para o qual convergem os interesses dessas pessoas. A banda permitiria que as competências particulares dos músicos sejam potencializadas na interação, produzindo com isso um bem distinto, que é do interesse de cada um, mas que jamais se alcançaria se exercessem as habilidades musicais isoladamente. Poderia se sugerir, nesse exemplo, que a banda representa um bem convergente para os músicos. Todos alcançam um fim que lhes dá satisfação, fruto da interação das habilidades musicais. $O$ interesse particular pela produção musical é potencializado pelo resultado da música produzida pela banda.

Para Taylor, esse contexto ilustra de partida uma concepção atomista. O motivo é porque concebe as interaçóes dos agentes como resultado de motivaçóes intrinsecamente individualistas, de tal forma que açóes sociais, por mais coletivas que pareçam, em última análise, seriam a expressão de propósitos individuais alcançados por intermédio da mediação social. A banda musical seria um exemplo. $O$ trabalho em equipe nas iniciativas econômicas empresariais públicas e privadas, em geral, seria outro. As práticas sociocomunitárias ou os bens tidos como coletivos se explicariam por 
intermédio do fato da convergência de diferentes interesses ou bens. Os bens e interesses coletivos seriam, por excelência, bens convergentes.

Conceber que todos os bens e interesses coletivos sejam convergentes Taylor julga um reducionismo equivocado. $\mathrm{Na}$ sua visão, existem bens que o homem persegue de um ponto de vista individual, mesmo na dimensão das interaçôes coletivas, e existem bens que são intrinsecamente coletivos, que o homem persegue como bens intrinsecamente sociais. O problema é que se convenciona hoje serem todos os bens coletivos a expressão de bens individuais, o que é uma falsa interpretação ou, ao menos, uma deliberada justificativa de um modo de conceber a sociedade. Na sua avaliação, a defesa desse ponto de vista, em grande medida, é feito no plano da economia, onde é considerada “[...] verdade auto-evidente no agregado de pensamentos, cálculos e reflexóes chamado de "economia do bem-estar social"' e no contexto de um influente pensamento filosófico que nos últimos três séculos tem ocupado um grande espaço na cena intelectual e que se pode "[...] denominar imprecisamente 'utilitarismo" (TAYLOR, 2000c, p. 143). Portanto, na perspectiva de Taylor, tanto no campo da economia, como no da filosofia, haveria fortes mecanismos de sustentação de um modo individualista de sociedade.

A justificativa desse ponto de vista, que ora se chama bem-estarismo ou utilitarismo simplesmente e indistintamente, se daria por intermédio de três pilares filosóficos, que são o consequencialismo, o utilitarismo e o atomismo. Para Taylor, em primeiro lugar, a justificativa do ponto de vista individualista, segundo o consequencialismo, ocorreria com a defesa da tese de que todos os juízos de valor, em última análise, devem avaliar resultados e estados de coisas. Seria fictícia a tentativa de defender o ponto de vista de que haveria uma qualidade moral intrínseca nos atos, como, por exemplo, aquilo que podemos considerar uma virtude. Por isso, a base dos julgamentos morais seria a consideração racional que se faz dos resultados das açôes, numa perspectiva individual. Em segundo lugar, a tese individualista seria defendida pelo utilitarismo, com a sustentação da tese de que "[...] os estados de coisas devem ser avaliados por sua utilidade, isto é, a felicidade ou satisfação que dão a agentes." (TAYLOR, 2000c, p. 144). Neste caso, a ideia de felicidade a ser valorizada não seria a que idealmente é apresentada por discursos morais de autoridades, como poderia ser a expressa por uma doutrina religiosa, mas aquela que as pessoas mesmo julgam como sendo satisfatória. Novamente, tratar-se-ia de manifestaçóes sobre a felicidade emitidas por juízos de agentes individuais. Finalmente, o atomismo contribuiria para a defesa do ponto de vista 
individualista em virtude da apologia da tese de que as únicas utilidades que contam na ponderação dos estados de coisas são as de indivíduos. Conforme esse ponto de vista, os indivíduos são os que ponderam os estados de coisas, são eles que, através da maneira racional de avaliar, consideram o que é útil. Para muitos, esse argumento aparece como óbvio, pois está estreitamente ligado às bases filosóficas dos dois primeiros argumentos.

Evidentemente, Taylor não ignora o fato de que tanto a teoria bemestarista econômica, como a teoria utilitarista propriamente dita, reconheçam que existam bens públicos. No conjunto dessas teorias e práticas, os bens coletivos têm o seu lugar. Como afirma Taylor,

[...] há claramente medidas, instituiçốes ou estados de coisas que oferecem satisfação a mais de um indivíduo. E em alguns casos essas satisfaçôes não podem, dada a natureza das coisas, ser produzidas de uma maneira que beneficie um único indivíduo, mas têm de beneficiar muitos ou nenhum (TAYLOR, 2000c, p. 145).

Exemplos de bens que beneficiam mais indivíduos são a "defesa nacional" de um país, uma "represa” de contenção de águas de um rio que impede que, em períodos de cheias, as propriedades de várias pessoas sejam inundadas etc. Haveria, por isso, bens coletivos, sob a ressalva de que em todos eles os beneficiados são sempre os indivíduos. Mesmo que não seja possível identificar expressamente quem são estes, como no caso da "defesa nacional", por exemplo, sabe-se que esses bens promovem a satisfação de indivíduos.

Na visão de Taylor, aqui se encontra o aspecto "crucial" da defesa dessa tese, porque os bens públicos e sociais se apresentariam como "decomponíveis" (TAYLOR, 2000c, p. 145) . Obedecendo à lógica da concepção atomista de que as "totalidades" são inexoravelmente compostas de "partes", na base de cada bem público ou social se encontrariam os indivíduos, os quais seriam, em última análise, os responsáveis de sua existência. A esse respeito Taylor se expressa, ressaltando que

[...] os eventos e estados que constituem o objeto de estudo na sociedade são compostos em última análise dos eventos e estados dos indivíduos componentes. No final, só indivíduos fazem escolhas e agem. Pensar que a sociedade consiste em alguma outra coisa, acima e além dessas escolhas e açóes individuais, é invocar alguma entidade estranha e mística, um espírito espectral da coletividade, com que nenhuma ciência sóbria e respeitável quer ter algo a ver. (TAYLOR, 2000c, p. 145). 
$\mathrm{Na}$ base dos bens coletivos estariam, portanto, átomos sociais, aos quais os bens e estados de coisas podem ser referidos. Tal compreensão denota uma das características centrais do "individualismo metodológico" (TAYLOR, 2000c, p. 145), que sustenta com vigor a tese de que todas as coletividades, em última análise, são compostas por indivíduos. Essa concepção parece mesmo ser de uma grande clarividência, a qual, dificilmente, se poderia contrariar. Concorre para a sua sustentação o fato óbvio de que, no fundo, as sociedades humanas são compostas por seres humanos, e nada mais. Mesmo ao estudar mais profundamente o seu funcionamento e se constatar que elas são animadas por componentes como papéis, cargos, status, regras, leis e costumes etc., tem que se admitir que, na base dessas estruturas, estão sempre os indivíduos. Ou, se se quiser argumentar de outro modo, na base deles se encontram pensamentos e açôes de indivíduos, que, em última análise, animam a sua existência. $\mathrm{Na}$ concepção de Taylor, tal argumentação parece ser inquestionável: “[...] os papéis e as coisas a eles equivalentes requerem pensamentos. E os pensamentos ocorrem como eventos na mente de indivíduos. Até agora tudo é verdade" (TAYLOR, 2000c, p. 147). O problema é que não se chega ainda a uma justificação plausível do atomismo. Na sua visão, o erro que cometem aqueles que sustentam essa tese reside no descaso pela "[...] natureza peculiar dos pensamentos (e, por conseguinte, de todas as coisas que requerem pensamento para existir)" (TAYLOR, 2000c, p. 147). Para Taylor, a verdadeira atenção que se deveria dar é ao fato de que os pensamentos possíveis de serem formulados existem na "[...] dimensão do significado, requerendo um pano de fundo de significados disponíveis a fim de ser os pensamentos que são” (TAYLOR, 2000c, p. 147) . E tais significados não são de inteira responsabilidade dos indivíduos.

Nesse contexto, Taylor invoca o segundo Wittgenstein, o qual representa a figura central da filosofia contemporânea que alterou significativamente a compreensão que se tinha acerca do pensamento e da linguagem. Com a utilização da imagem do jogo, sua contribuição teria sido decisiva para entender a atividade humana regida por regras, em que surgem questóes de validade e de não-validade. Por maiores que sejam os questionamentos a tal teoria, Taylor assevera que ela ainda se justifica, pois, no seu entendimento, “[...] encontramo-nos no domínio da validade" (TAYLOR, 2000c, p. 148). Como num jogo, onde o movimento dos elementos (das peças) pressupóe um pano de fundo de regras, a linguagem depende de condiçóes de validade, que autorizam ou não os enunciados. Entretanto, tal autorização não depende dos jogadores, mas sim das regras existentes. 
O que Taylor visa com essa distinção é situar o erro da interpretação atomista que assimila todos os bens e estados de coisas sociais a uma dimensão de "eventos puros e simples", sem se dar conta da existência e pertinência dos "eventos de significado" (TAYLOR, 2000c, p. 149), os quais melhor os caracterizariam. Taylor ilustra seu argumento com exemplos. Num primeiro momento, faz alusão aos romances históricos ruins, nos quais um personagem ambientado na Idade Média, por exemplo, interrompe um curso de ação por considerá-lo "gratificante" ou, num outro, se um homem de um romance ambientado numa cidade neolítica se refere a sua amada como alguém "sofisticado". Em ambos os casos, salta aos olhos a incongruência das narrativas. A primeira, porque a compreensão de mundo medieval interditava o senso de realização humana como um bem em si; a segunda, porque os homens do neolítico se encontravam numa situação extremamente rudimentar de desenvolvimento tecnológico, a qual lhes impedia atribuir um adjetivo ambientado no contexto de personagens que vivem em pleno desenvolvimento do século XX. Como afirma Taylor, em "[...] ambos os casos, sabemos que eles "não poderiam” estar dizendo/pensando/fazendo o que é descrito." (TAYLOR, 2000c, p. 147). Em ambos os casos, a incongruência maior não se dava em virtude da falta de algum artefato para que pudessem remediar a dobra do tempo, mas porque, no final das contas, esses significados não existiam para eles e, portanto, não poderiam ser formulados dessa maneira. Eles ainda não eram parte do pano de fundo das descriçóes possíveis do mundo que lhes poderia permitir classificar as coisas como gratificantes ou sofisticadas, bem como seus opostos e alternativas (TAYLOR, 2000c, p. 147). Na realidade, para que pensamentos possam ser formulados, eles pressupóem e requerem um pano de fundo de significados, ao qual os agentes pensantes têm acesso por pertencerem a uma determinada comunidade linguística, situada num tempo e espaço delimitado. Sem essa condição, eles não seriam possíveis.

O argumento de Taylor concernente aos exemplos expostos é o de que, num sentido forte, alguns pensamentos são impossíveis em certas circunstâncias (TAYLOR, 2000c, p. 148). Tem de haver um conjunto de significados, para que eles sejam possíveis. No exemplo da consideração de que uma pessoa "seja sofisticada" numa comunidade de lavradores do período neolítico superior, nada pode contar como sendo plausível nessa circunstância. Num jogo de xadrez, certos movimentos do cavalo, em linha reta, à semelhança do movimento dos bispos, por exemplo, são interditados. Tudo isso porque o movimento das peças do jogo pressupóe um pano de fundo de regras, bem como, no caso da linguagem, pressupóe condiçóes de 
possível validade. Através dos argumentos de Wittgenstein, Taylor fortifica a sua tese de que os eventos de pensamento pressupóem um pano de fundo de significado, ao qual os agentes constantemente se remetem, como no caso dos itens linguísticos, que somente têm o significado que possuem contra o pano de fundo de uma linguagem inteira. Taylor faz menção aos argumentos wittgensteinianos de contestação de uma "linguagem privada" e das limitaçóes da "definição ostensiva". Em seguida, reporta-se ao erro das teorias do significado que dominaram o início da filosofia moderna, como as elaboradas por Hobbes, Locke e Condillac. ${ }^{7}$ Para este último, por exemplo, a origem da linguagem se daria através do esforço dos primeiros homens em usar uma primeira palavra, em seguida outra, para se reportarem a significados e, aos poucos, progressivamente, frases inteiras seriam formuladas. Tudo isso seria possível por intermédio da ação individual de associar certos sons a certas ideias na mente. $\mathrm{Na}$ visão de Taylor, encontra-se aqui uma "concepção ingênua" (TAYLOR, 2000c, p. 149) da linguagem. Precisamente, porque é feita uma "[...] assimilação do pensamento e do uso da linguagem a tipos ordinários de eventos que não requerem um pano de fundo de significado." (TAYLOR, 2000c, p. 149). A assimilação equivocada reside no fato de não ser corretamente feita a distinção entre eventos de significado e eventos que ele chama de "puros e simples". Um evento de significado é precisamente o do exemplo da impossibilidade de uma comunidade do neolítico pensar que uma pessoa possa ser "sofisticada". Ao passo que um evento "puro e simples" seria o que ilustra a situação da impossibilidade de uma comunidade do neolítico construir pirâmides nas proporçôes e grandezas da civilização egípcia, pelo fato de não possuírem o contingente de mão-de-obra escrava que na época havia. A confusão promovida pelas primeiras teorias da linguagem reside na assimilação de que a junção entre pensamento e palavra se dá como eventos "puros e simples". Eles ignoravam por completo que pudessem existir eventos de significado. Para uma comunidade neolítica, a impossibilidade de

\footnotetext{
7 Taylor valoriza a concepçáo romântica de linguagem, de cunho herderiano. No lugar de a linguagem ser vista como um mero instrumento para descrever as coisas, ela é vista como uma forma de criação do mundo. Segundo Taylor, "[...] é crucial para a teoria romântica o fato de ele (sic) acentuar a natureza constitutiva da linguagem. Esta não é vista primordialmente como um instrumento mediante o qual ordenamos as coisas de nosso mundo, mas como aquilo que nos permite ter o mundo que temos. A linguagem torna possível o desvelamento do mundo humano. Há aqui uma combinação de criação e descoberta que não é fácil definir"(TAYLOR, C. Argumentos filosóficos. Trad. de Adail Ubirajara Sobral. São Paulo: Loyola, 2000b, p. 09, Prefácio). Em A importância de Herder, Taylor faz uma detalhada exposição da forma como Condillac concebia a linguagem e como Herder a criticou (Cf. TAYLOR, C. A importância de Herder. In: Paulo: Loyola, 2000a, p. 93-114.) . Argumentos filosóficos. Trad. de Adail Ubirajara Sobral. São
} 
construir pirâmides à semelhança dos egípcios, dentre vários aspectos, é o fato empírico de não ter a mão-de-obra existente no Egito antigo, mas poderia ser também a necessidade premente para esses povos de suprir as necessidades básicas, uma vez que no Egito já havia excedentes. A confusão promovida pelas primeiras teorias da linguagem seria precisamente o erro que subjaz ao atomismo moderno e ao individualismo metodológico. "Uma vez que se diga que todos os pensamentos ocorrem em mentes individuais, podemos pensar que a defesa do individualismo metodológico já está suficientemente feita. Mas isto só se basta se os estivermos tratando como eventos puros e simples" (TAYLOR, 2000c, p. 149), o que não é o caso. Taylor mostra que há um espectro amplo de elementos que devem ser levados em conta. Por isso, "[...] uma vez que percebemos que lidamos com eventos de significado, a história fica mais complicada. Não podemos simplesmente tomar por foco o evento que ocorre; temos também de levar em conta o pano de fundo que lhe confere seu significado." (TAYLOR, 2000c, p. 149). E, nesse ponto, a novidade surge como imponderável, pois o pano de fundo "[...] não é um evento, nem pode se localizar em indivíduos. Trata-se de uma linguagem e localizá-la não é tarefa simples. De um ponto de vista, é impossível localizá-lo." (TAYLOR, 2000c, p. 150). Mas, sob outro, Taylor sugere que, de fato, a linguagem se apresenta como algo que é criado e mantido pelos intercâmbios contínuos dos falantes de uma comunidade linguística e que esta, no final das contas, "é o lócus" (TAYLOR, 2000c, p. 150) da comunicação. As trocas realizadas numa comunidade linguística constituem o espaço primordial da comunicação ${ }^{8}$. E é precisamente essa concepção que é rejeitada pelo individualismo metodológico.

$\mathrm{Na}$ concepção tayloriana, eventos de significado só existem porque se situam num espaço bidimensional: “[...] são eventos particulares, mas só em

\footnotetext{
8 Jessé José Freire de Souza explora esse argumento. Na sua visão, o núcleo do argumento comunitarista de Taylor se encontra no fato da anterioridade da língua. Ou seja, os sujeitos somente existem enquanto relaçóes comunicativas. Elas definem o que são os sujeitos enquanto tais, pois " [...] constituem o horizonte ético e situacional que conferem o contexto inextricável para a construçáo das suas identidades e, portanto, das suas açóes no mundo" (SOUZA, Jessé José Freire. Charles Taylor e a relaçấo entre cultura, democracia e reconhecimento social. In: OLIVEIRA, Nythamar Fernandes de; SOUZA, Draiton Gonzaga de (Org.). Justiça e politica: homenagem a Otfried Höffe. Porto Alegre: EDIPUCRS, 2003, p. 607). Concernente às relaçōes comunicativas, é importante observar que Taylor difere de Habermas sobre o tema, em virtude de entender que os eventos de significado constituem o núcleo de identidade a partir do qual os agentes fazem suas escolhas. Para Taylor, a ética do discurso de Habermas transforma o cidadão em um ser de razão sem paixôes e reduz a sociedade a uma sociedade de pensamento. Habermas pressupóe, também, a possibilidade formal de um ponto de vista excêntrico e universalizável do agir. Já para Taylor, a única coisa que existe é o pano de fundo de significado, que, embora tenha estabilidade, é dinâmico e se formula e se refaz, paulatinamente, ao longo da história.
} 
relação a um pano de fundo de significado." (TAYLOR, 2000c, p. 150). Nesse quesito, Taylor se ancora na distinção saussuriana entre langue e parole, porque ela lhe aporta excelentes contribuiçóes na defesa da tese principal. $\mathrm{Na}$ visão de Saussure, a linguagem somente pode ser compreendida sob a tutela dessa distinção. De um lado, existe a langue, que é o código ao qual se recorre em cada ato de fala particular. De outro a parole, que são os atos de fala efetivos circunscritos ao código pré-existente. Há uma relação de interconexão entre ambos, de tal forma que um existe por intermédio do outro. Os atos de fala pressupóem o código, que constantemente é recriado por intermédio deles. Todavia, a langue, em relação aos atos de fala, é uma estrutura ideal, a qual "sincronicamente" sempre se reporta à parole. Com o passar do tempo, "diacronicamente" a langue muda, em virtude da açáo da parole, que, com os erros e a inovaçóes introduzidas por esta, torna o uso desviante aos poucos padrão. $\mathrm{Na}$ realidade, os atos de fala são sempre dos indivíduos, por isso se poderia, apressadamente, dizer que a parole é decomponível. Na perspectiva tayloriana, contudo, este não é o caso. Se considerarmos com mais atenção, constata-se que um relato atomista da linguagem não se sustenta, uma vez que a langue não é uma estrutura individual, de indivíduos, mas uma "[...] prática normativa de uma comunidade" (TAYLOR, 2000c, p. 150). Do mesmo modo, não contribui para contestar a presente tese o argumento de que, no final da contas, a langue somente é do modo que se encontra devido aos atos de parole e que, portanto, ela seria decomponível, já que se trata dos atos de $\mathrm{A}$, de $\mathrm{B}$, de C etc. $\mathrm{O}$ fato, na realidade, é que os atos de parole que modificam a langue somente se comportam assim porque são atos contra o pano de fundo de um código estruturado numa época determinada. Portanto, eles se moldam em relação a um código estável. $\mathrm{O}$ individualismo metodológico desconsidera essa diferença, comportando-se como se fosse possível ignorar o pano de fundo, tratando os atos de parole como se fossem todos eventos puros, ou, simplesmente, como se fosse possível reduzi-los e decompô-los em simples atos individuais.

Na concepção tayloriana, fazer uma correta leitura dessa estrutura bidimensional dos eventos de significado consiste num "[...] passo crucial que nos faz sair do atomismo." (TAYLOR, 2000c, p. 151). O motivo reside nas vantagens interpretativas que aporta, para construir em bases sólidas uma ontologia social na qual a dimensão da langue apareça com autonomia em relação às ocorrências individuais. Em outras palavras, é através desse argumento que bens irredutivelmente sociais poderiam ser compreendidos em toda a sua extensão, pois papéis sociais, leis, cargos, status etc. se comportam como o análogo da estrutura codificada da langue. Por exemplo, o exercício de um 
papel social, como o de professor, não é um estado puro e simples, mas uma estrutura codificada de significado. Assim, "[...] só posso cumprir esse papel porque há condiçôes de validade definidas no conjunto de práticas e instituiçôes que moldam a vida da minha sociedade" (TAYLOR, 2000c, p. 151). O modo como alguém cumpre esses procedimentos, a maneira como obtém êxito ou fracasso, desencadeia alteraçóes diacrônicas no conjunto desses elementos, que possuem uma certa estabilidade. De um modo semelhante ao que se passa com a relação entre parole e langue, cada indivíduo cumpre um papel social, que pressupoóe uma estrutura de significado dada; esta, por sua vez, é mantida e cultivada por intermédio de incessantes intercâmbios da vida social, que renovam constantemente a estrutura de significado. Na concepção de Taylor (2000c, p. 152), "[...] o círculo saussuriano aplica-se aqui também, e não podemos reduzilo sem nos tornar incapazes de compreender como funcionam as sociedades".

$\mathrm{Na}$ sua compreensão, as sociedades comportam-se como no esquema da relação entre parole e langue. De um ponto de vista geral, todos os atos e escolhas são individuais. Mas, de um ponto de vista estrito, todos os atos e escolhas só existem como tais "[...] contra um pano de fundo de práticas e compreensōes” (TAYLOR, 2000c, p. 152). Contudo, essa estrutura mais estável não pode ser reduzida a estes atos e escolhas. Ela subsiste como a langue, ou seja, como um núcleo indecomponível que serve de referência aos atos e escolhas particulares, aos quais os atos e escolhas particulares se remetem.

Com esse conjunto de argumentos, Taylor espera ter apresentado razóes para o desmantelamento da tese de que os bens sociais tenham de ser decomponíveis. Resta agora demonstrar como o argumento funciona. Afinal, como se pode identificar que um bem é irredutivelmente social?

Taylor indica dois argumentos. O primeiro retrata o caso dos bens de uma cultura que tornam certas ações, sentimentos e modos de vida valorizados como compreensíveis. O segundo trata de bens "[...] que incorporam essencialmente compreensōes comuns de seu valor" (TAYLOR, 2000c, p. 155). Entre eles, existe uma relação de reciprocidade, de modo que, quando um aparece, o outro está igualmente presente. Concernente à cultura, Taylor entende que ela se comporta como o análogo da langue, no sentido de que ela é o locus de bens. Quando, por exemplo, valorizamos certas coisas, julgamos que certas ações são boas ou negativas, que certas experiências são gratificantes, fazemos tais julgamentos à luz do pano de fundo que representa nossa cultura. Isto é, a cultura se comporta como a langue nas diferentes valorizaçóes ou interdiçóes que damos a certas açóes. Se temos o sentimento de gratificaçáo oriundo da 
valorização da autoexpressão autêntica ou da experiência adquirida de uma obra de arte, nós o fazemos sempre diante de um pano de fundo de cultura no qual vivemos. Taylor dá o exemplo das atitudes de franqueza e igualdade, que pautam as expectativas de comportamento das pessoas, asseverando que elas somente fazem sentido numa compreensão de pano de fundo desenvolvida em nossa cultura. Ou seja, em certas culturas tais atitudes são valorizadas. Numa sociedade diferente, que poderia ser a de uma sociedade hierárquica do Japão medieval, por exemplo, elas poderiam não ter sentido. Atitudes de franqueza e igualdade poderiam, nessa sociedade, ser valorizadas numa perspectiva restrita, como em pequenos círculos de amizade, mas nunca numa perspectiva de que fossem um valor para todos os cidadáos. Se atitudes de franqueza e igualdade são bens, sem considerar outras variáveis, perfeitamente se pode afirmar que é a cultura que os torna possíveis. Por isso, Taylor sustenta que, "[...] se quero maximizar esses bens, tenho de querer preservar e fortalecer essa cultura. Mas a cultura como um bem, ou, mais cautelosamente, como o lócus de alguns bens (porque pode haver também muitos bens que são repreensíveis), não é um bem individual" (TAYLOR, 2000c, p. 153).

Taylor faz a ressalva de que a cultura é o resultado de diferentes valorizaçóes promovidas por um número extenso de pessoas, mas que, a despeito dessas valorizaçôes individuais, não se pode concluir que tenha um caráter subalterno aos átomos de intercâmbio individuais que a promovem. Ela possui uma estrutura própria, que resulta da troca que muitos indivíduos fazem para valorizar certas atitudes, embora nunca se comporte como o resultado da mera soma dessas valorizaçóes, mas como uma estrutura que delas emerge e adquire vida própria, aos quais os indivíduos se reportam em suas valorizaçóes. A cultura, em si, pode ser também o espaço de bens questionáveis. Ela abarca valoraçóes cujo teor argumentativo não se sustenta sob determinadas premissas, as quais podem ser consideradas repreensivas, como um não-bem. A ideia principal, contudo, é a de que a cultura se comporta como a langue nas diferentes valorizaçóes ou interdiçôes que damos às açôes, sendo por isso indecomponível. E, nesse sentido, ela náo deixa de ser também um bem de uma determinada comunidade, uma vez que constitui o lócus no qual os atos e as experiências humanas se tornam inteligíveis. Em consequência, a cultura não seria um mero instrumento para a promoção e afirmação de bens, como poderia ser o caso de um bem social como uma "represa" de contenção das águas de um rio para proteger os habitantes de possíveis inundaçóes. A represa pode, sim, ser considerada um instrumento, visto que ela não é, em si, um bem, mas somente seus efeitos se comportam como um bem. $\mathrm{O}$ mesmo raciocínio, contudo, não se aplica à cultura. Taylor 
entende, sob esse aspecto, que "[...] a cultura tem um vínculo essencial com aquilo que identificamos como bem" (TAYLOR, 2000c, p. 153), condição que a impede de ser vista como um mero instrumento para a promoção de bens. Dessa forma, ela é em si um bem, não no sentido enfraquecido, mas intrinsecamente.

Com essas consideraçóes se entra agora no segundo argumento de Taylor, que diz respeito aos bens que incorporam essencialmente compreensóes comuns de seu valor, como é o caso de exemplos por ele examinados aos quais se junta, em parte, a própria "cultura", mas, sobretudo, a "amizade", o "reconhecimento mútuo no amor" e as "relaçôes francas e igualitárias" no contexto social. Em síntese, o que esses bens compartilham é o fato de serem bens "genuinamente comuns", e não somente bens convergentes. Taylor assim se expressa: "[...] uma questão convergente é a que tem o mesmo significado para muitas pessoas, mas onde isso não é reconhecido entre elas ou no espaço público. Uma coisa é comum quando existe não só para mim e para você, mas para nós, sendo reconhecida como tal" (TAYLOR, 2000c, p. 155). No caso das "relaçôes francas e igualitárias", o que sucede é que esse tipo de relação não é algo que concerne apenas a um indivíduo, como se se pudesse garantir que se trata de um bem para este ou para aquela pessoa. Não é em decorrência de nossas relaçôes serem desse modo como mera combinação de um fato sobre mim, sobre minha disposição e a de outro, como se fosse possível concluir que esse tipo de relação existe somente pela soma de distintas disposições de querer promover relaçôes francas e igualitárias. Para Taylor, há algo a mais, que consiste na compreensão comum que temos sobre esse tema. E essa compreensão comum e mútua náo pode ser explicada pela mera soma de diferentes estados individuais. Um bem social não pode meramente ser explicado pelo fato de ele se comportar como um bem para $\mathrm{A}$, para $\mathrm{B}$, para $\mathrm{C}$ e uma série de indivíduos. Embora esse argumento seja coerente em algumas situaçóes, ele não se aplica a todas elas, como quer a teoria utilitarista que embasa o bem-estarismo. $\mathrm{Na}$ perspectiva de Taylor, o ponto crucial a observar é o de que uma compreensáo comum é indecomponível. E a justificativa reside no fato de ela não ter este status somente pelo fato de ser para mim ou para você, mas pelo fato de ser para "nós". A esse respeito, salienta Taylor (2000c, p. 155): "[...] o fato de termos uma compreensão comum pressupóe que formamos uma unidade, um "nós" que compreende junto, que é por definição analiticamente indecomponível. Se o fosse, a compreensão não seria genuinamente comum". Esta é a situação da relação de amizade, que tem por sustentação a compreensão comum daqueles que a cultivam como um bem e que, por isso, não pode ser explicada por uma mera análise atomista. Nesse sentido, a amizade não pressupóe somente 
uma compreensão mútua de que ela é um bem, mas algo que vai além, que consiste no fato de considerá-la como valiosa. Porém, esta é também a situação das relações francas e igualitárias no contexto social, já que as valorizamos decididamente pelo fato de haver uma compreensão comum a este respeito. Ou seja, as relaçóes francas e igualitárias são valorizadas porque, em última análise, há um sentido comum compartilhado entre os homens sobre o fato de serem iguais, sobre o fato de que merecem um tratamento igual e que esta é a melhor maneira de tratar o outro do ponto de vista social.

Bens sociais convergentes e bens irredutivelmente sociais podem ser assim identificados. A tendência utilitarista dominante, com forte presença na teoria bem-estarista econômica, promove a assimilação de todos os bens como bens convergentes, justificando de uma forma simplória uma visão de sociedade e de política que privilegia o ponto de vista instrumental de todos os bens. Na perspectiva tayloriana, tal situação promove a dissimulação e erros significativos na valorização de situações de forte identidade coletiva. $O$ que Taylor visa pôr em evidência é o fato de que não só elas existem como se torna importante fazer uma correta leitura da identidade coletiva, para valorizá-las e pensar a democracia liberal para além do procedimentalismo democrático, que reduz a esfera pública a simples atos individuais - para o bem-estarismo, todos os bens têm de ser individuais. As vantagens que lhe aportam é lançar bases para reforçar a perspectiva comunitarista social, à qual se alia, e, por outro, colocar em destaque a defesa do argumento de que a estabilidade e a unidade das instituiçóes democráticas têm a sua garantia num modelo liberal democrático de primazia dos direitos coletivos, para a valorização da comunidade de valores compartilhados.

Em que termos se pode afirmar que há uma influência de Hegel sobre a leitura tayloriana de bens sociais?? Certamente, uma perspectiva central

\footnotetext{
9 A influência de Hegel sobre Taylor, além de ser reconhecida pelo próprio pensador, é assinalada por alguns de seus leitores. Quanto ao tema em questão, Janie Pélabay entende que Taylor retoma a distinção hegeliana entre "vontade comum" e "vontades coincidentes", ao insistir sobre o fato de que "[...] certas significaçôes, açôes e valores não são convergentes, mas autenticamente comuns" (PÉLABAY, Janie. Charles Taylor, penseur de la pluralité. Laval et Paris: Les Presses de l'Université de Laval et L'Hartmattan, 2001, p. 189). No Brasil, Paulo Roberto Monteiro Araújo realizou um estudo aprofundado sobre o tema. Ele afirma que, "[...] ao por a questáo da linguagem na ordem do dia do pensamento ocidental contemporâneo, Taylor procura criar uma nova linhagem de pensamento que consiga superar a instrumentalidade do pensamento ético-político." [...] "É contra o esquema da instrumentalidade que Taylor, a partir das suas raízes hegelianas, busca desenvolver a questão da linguagem nâo como simples meio designativo" (ARAÚJO, Paulo Roberto Monteiro de. Charles Taylor: Para uma ética do reconhecimento. 2003. Tese (Doutorado) - UNICAMP, Campinas, São Paulo, 2003. Disponível em: http://libdigi.unicamp.br/document/?code=vtls000302117. Acesso em: 2 nov. 2009.)
} 
que Hegel concordaria é a de que "[...] toda a ação não é em última análise efetuada por indivíduos" (TAYLOR, 2000c, p. 109), no sentido de que ela caberia exclusivamente a eles. $\mathrm{Na}$ ação humana, para Hegel, concorrem elementos do "espírito de um povo" ${ }^{10}$, do "espírito do mundo"11, da "razão que governa a história" 12 , captada e exposta, sobretudo, pelos homens históricos e cuja tematização recebe uma explicitação no argumento do ardil da razão. ${ }^{13}$ De outra parte, Hegel concordaria, à semelhança de Taylor, que "açôes irredutivelmente coletivas" (TAYLOR, 2000c, p. 109) existem. Sua presença aparece na crítica que faz à perspectiva atomista de fundamentação da vida política por intermédio do contrato social ${ }^{14} \mathrm{e}$, fundamentalmente, na concepção de Estado como um todo orgânico, cuja soma das partes não expressa a identidade do todo. Esses argumentos apresentam uma forte valorização da ontologia social, tal como Taylor a pensa.

Mas, a assimilação de Taylor da concepção hegeliana de sociedade, na perspectiva da defesa de bens de forte identidade coletiva, aparece na leitura da noção de "eticidade" ${ }^{15}$ Segundo essa concepção, o espaço da ação humana é essencialmente um espaço mediatizado pelas relaçóes sociais construídas e em construção, presentes em diferentes instituições, como a família, a sociedade

10 "Der Geist in der Geschichte ist ein Individuum, das allgemeiner Natur, dabei aber ein bestimmtes ist, d. h. ein Volk überhaupt; und der Geist, mit dem wir es zu tun haben, ist der Volksgeist" (HEGEL, G.W.F. Vorlesungen über die Philosophie der Weltgeschichte, Band I: Die Vernunft in der Geschichte. Hrsg. von J. Hoffmeinster. Hambourg: F. Meiner, 1980, p. 59.

11 "Der Volksgeist ist zugleich wesentlich ein besonderer, zugleich nichts als der absolute allgemeine Geist, - denn der ist Einer. Der Weltgeist ist der Geist der Welt, wie er sich im menschlichen Bewusstsein expliziert. [...] Und dieser Weltgeist ist gemäss dem göttlichen Geiste, welcher der absolute Geist ist. (Ibid., p. 60.) Ver também parágrafo 344 da Filosofia do Direito de Hegel (Cf. HEGEL, G.W.F. Grundlinien der Philosophie des Rechts, hrgs. von J.Hoffmeister. Hamburg: F. Meiner, 1955, p. 290).

12 “... dass die Vernunft die Welt regiere, und das Mangelhafte" (HEGEL, 1980, p. 38).

${ }^{13}$ Povos e indivíduos agem em vista de seu bem próprio. Mas, assim fazendo, servem inconscientemente para realizar uma tarefa maior. Essas consciências individuais agem, então, sem o saber e querer, a serviço de algo que lhes ultrapassa. É isto que Hegel chama de "ardil da razáo". Quer dizer, o fato de a razão se realizar por intermédio de homens que agem de uma forma apaixonada. Segundo Hegel, "[...] das Besondere hat sein eigenes Interesse in der Weltgeschichte; es ist etwas Endliches und muss als solches untergehen. Es ist das Besondere, das sich aneinander abkämpft, und wovon ein Teil zugrunde gerichtet wird. Aber eben im Kampf, im Untergange des Besondern resultiert das Allgemeine. Dieses wird nicht gestört. [...] Man kann es die List des Vernunft nennen, dass sie die Leidenschaften für sich wirken lässt, wobei das, durch was sie sich in Existenz setzt, einbüsst und Schaden leidet" (HEGEL, 1980, p. 105).

14 Ver HEGEL, 1955, Zusatz von $\$ 2$, p. 19-21.

${ }^{15}$ A eticidade é definida por Hegel como "[...] o conceito da liberdade tornada mundo presente-aí e natureza da consciência de si” (HEGEL, G.W.F. Encyclopédie des sciences philosophiques. Texte intégral présenté, traduit et annoté par Bernard Bourgeois. Tomes III - édition 1830. Paris: Vrin, $1988 \$ 513$, p. 299). 
civil, a esfera público-estatal, o direito etc. Nesse contexto, segundo Taylor, Hegel autoriza uma concepção de vida pública desenvolvida no seu sistema de moralidade objetiva (Sittlichkeit) (HEGEL, 1955, p. 142-297) como compreensão da ação humana enquanto "efetiva" e "expressiva". O termo "efetivo" tem a ver com o conceito de Wircklichkeit, amplamente utilizado por Hegel em sua Filosofia do Direito, que denota um sentido da realidade como eminentemente ativo e racional. O termo "expressivo", embora não utilizado explicitamente por Hegel, representa com justeza para Taylor a ideia oriunda de Herder de que a vida do espírito é um análogo à obra de arte, na qual um elemento somente tem significado na relação aos demais. O próprio indivíduo em sociedade, por mais que tenha sua identidade distinta dos demais, é uma expressão interacional, formada pelo confronto e a assimilação de pontos de vista de uma série de outros indivíduos. A sua identidade é construída, assim, pela negação da identidade de outros, como autodeterminação diferenciada, e pela negação de sua própria identidade, portanto, como afirmação de sua identidade pela autonegação de determinaçóes julgadas anacrônicas. Nesse sentido, o espírito, ou o indivíduo, são livres quando e porque se autodeterminam. E autodeterminar-se é expressar-se como uma atividade do pensamento. De acordo com Hegel, tal atividade é a que permite aos indivíduos serem uma expressão interior cada vez mais clara de si.

A herança hegeliana da ideia de eticidade possibilita a Taylor pensar a questão de bens sociais na perspectiva da afirmação de bens irredutivelmente sociais, através da distinção entre dois níveis principais da ação humana. De um lado, Taylor distingue a perspectiva do agir causal; de outro, o agir qualitativo. $\mathrm{Na}$ sua interpretação, que aqui se mostra herdeiro da visão embrionária da teoria da ação na filosofia de Hegel ${ }^{16}$, a concepção de que toda ação humana no contexto social se dá como a soma de diferentes intençôes ou desejos caracteriza a perspectiva causal da ação. Já a concepção de que o agir humano se revela como o resultado de um contexto histórico-cultural, que não é possível abstrair de toda e qualquer influência, como se pudesse alcançar um patamar de um sujeito ideal de conhecimento imune às influências, essa dimensão caracteriza a perspectiva qualitativa. Taylor encontra em Hegel elementos para sustentar esta última tese. ${ }^{17}$ De seu ponto de vista, intençôes individuais

\footnotetext{
${ }_{16}$ Para maiores detalhes, ver o artigo "Teoria da ação e mediações dialética em Hegel” (2011), de nossa autoria.

${ }^{17}$ Cf. Taylor, "Dans ce projet d'une histoire de la modernité, Hegel est évidemment incontournable, parce qu'il est le premier à avoir tenté une explication à la fois génétique et philosophique de son époque. Les théories du progrès des Lumières n'ont pas cette profondeur. Il y a une ébauche de cette perspective chez Ferguson et dans les Lumières ècossaises, mas c'est Hegel qui a entrepris de
} 
podem ser compartilhadas e, efetivamente, se encontram compartilhadas, a tal ponto que seria impossível designar quem se situa na origem de uma determinada concepção, pois ela seria de um domínio coletivo - a langue. Por isso, nesse contexto, seria possível falar de um interesse comum que vai muito além da convergência de interesses particulares, pois açôes irredutivelmente comuns seriam possíveis e desejáveis.

A Sittlichkeit de uma sociedade qualquer é a ação de uma comunidade onde o "eu" é um "nós" que é um "eu". O "eu” se apresenta essencialmente como um "nós", por ser um "eu" compartilhado, condição na qual ele funciona como "expressão" comum, e, por isso, veículo do modo de ser coletivo. Tal compreensão é um passo decisivo. Ela, contudo, não é suficiente. Para Taylor, Hegel ensina algo mais:

[...] a Sittlichkeit de uma sociedade dada não pode ser concebida unicamente como a açáo de uma comunidade, ou aquela de indivíduos enquanto eles se identificam tão somente como membros da comunidade [...], ela encarna e exprime igualmente certa compreensão do agente, de sua comunidade, de sua relação ao divino. (TAYLOR, 1997, p. 111).

Taylor assinala que a ação da comunidade em si exibe características do modelo qualitativo de ação, uma vez que póe em relevo o fato de a própria comunidade se reconhecer no que faz. Taylor se revela, assim, um herdeiro de Hegel, porque para ele a ação da comunidade revela a sua identidade. Taylor se refere a essa passagem, enfatizando que este reconhecer compreensivo revela "[...] a chave do destino da sociedade" (TAYLOR, 1997, p. 111), já que é a partir dele que a sociedade se projeta no futuro como um modo de ser que ainda não é. Tal condiçáo constitui o referente para que a sociedade possa se enxergar e se autocriticar. Conforme Taylor, “[...] é neste nível que a incoerência fundamental de uma prática social aparecerá como contradição, como se constata no caso da sociedade escravagista" (TAYLOR, 1997, p. 111). A diferença que se engendra entre uma prática social dada só é possível em virtude do distanciamento que ela mesma se proporciona, momento em que o contraste pode se revelar. Este é um aspecto fundamental, pois permite que a sociedade se veja diferente do que ela é. Hodiernamente, sociedades que

penser philosophiquement la diversité des cultures et leur histoire. On ne peut aborder l'histoire de la modernité sans d'abord régler ses comptes avec Hegel" (TAYLOR, C.; DE LARA, Philippe. De l'anthropologie philosophique à la politique de la reconnaissance. Entretien de Philippe de Lara avec Charles Taylor. In : LAFOREST, Guy; DE LARA, Philippe (Org.). Charles Taylor et l'interprétation de l'identité moderne. Quebéc/Paris: Les Presses de l'Université de Laval/ Le CERF, 1998, p. 355). 
não conseguem engendrar tal distanciamento se veem restritas ao seu modo de ser fluido, onde os indivíduos têm uma limitada apreensão coletiva de si, deixando-se guiar pelos projetos sociais elaborados por poucos tecnocratas, que, em consórcio com representantes políticos, em última análise, decidem o rumo da vida social.

Para Taylor, este não é o bom caminho, nem o seria aquele que a ontologia social hegeliana sugere. É o próprio Taylor que afirma: “[...] o desenvolvimento histórico em Hegel somente pode ser corretamente exposto se nós compreendemos as instituiçóes sociais deste modo, como açóes transindividuais e dotadas de uma dimensão expressiva" (TAYLOR, 1997, p. 111). O caráter transindividual e expressivo é que daria condiçôes para superar o engodo da concepçáo causal que sustenta o atomismo social como modo privilegiado de conformação social. Para a posição causal, açôes coletivas, como, por exemplo, a afirmação de que o partido X defende ou fez isto ou aquilo, equivale a pressupor que uma açáo convergente se produziu como resultado de agregados de indivíduos. Equivale a pressupor que o que torna esses eventos ações humanas é o fato de terem causas mentais internas, no sentido de que se produziu separadamente, em cada indivíduo, a mesma decisão. "A concepção causal é intrinsecamente atomista” (TAYLOR, 1997, p. 109), como aponta Taylor. O motivo é porque, em última instância, os atos seriam individuais, o que contraria a posição que admite açóes irredutivelmente coletivas. Para uma posição social atomista, a causa das ações é o desejo, a intenção, ou seja, um estado mental. "Estes estados mentais somente podem ser compreendidos como estados de indivíduos. O mental é o que é "interior", o que é de cada um dentre nós" (TAYLOR, 1997, p. 109). Por isso, na ação social, as açôes coletivas seriam resultado da açáo convergente de várias causas mentais de indivíduos. Nesse quadro de referência, a esfera pública seria a convergência de interesses individuais, onde o funcionamento das instituiçóes sociais seria explicado em termos puramente instrumentais. Na visáo de Taylor, "[...] nestes termos, a teoria de Hegel se torna completamente informulável" (TAYLOR, 1997, p. 109). A posição tayloriana é a de que Hegel interdita a leitura instrumental, porque ela se elabora no quadro da teoria qualitativa da ação. Dessa maneira, açóes comunitárias se diferenciam de açóes meramente coletivas pelo fato de se reconhecer a possibilidade de açóes irredutivelmente sociais. Uma teoria causal, no fim das contas, admite apenas açóes coletivas como resultado de açôes individuais, quer dizer, como resultado da convergência de vários indivíduos sobre um determinado ponto. Hegel seria contrário a essa posição, contribuindo, assim, para a afirmação da tese qualitativa da ação. 
A teoria de Hegel evidencia outro aspecto significativo da teoria da ação ligado à identificação de níveis de ação. Haveria três níveis distintos. Segundo Taylor, a ação pode ser individual, quando se trata de decisôes relativas à imediatez da conduta humana. Optar, por exemplo, por vestir esta ou aquela camisa para participar de um ato social. Embora se possa objetar que a escolha do formato ou das cores da camisa sofra uma influência sociocultural, pois é resultado de uma certa concepção historicamente determinada de camisa, o que colocaria em dúvida a consistência do argumento, a escolha da camisa, naquela ocasião, é feita por um indivíduo. A ação pode ser comunitária, concebida no modelo descrito nos parágrafos acima como um modo irredutivelmente social. E, em terceiro lugar, a ação pode ser a de um agente que não se pode dizer que em primeiro lugar é idêntico ao agir humano. De acordo com Taylor, “[...] existe para Hegel um nível essencial da atividade que não é somente supra-individual, mas é mais que simplesmente humano"(1997, p. 110). Tal situaçáo seria parcela do que fazemos, mas que imediatamente corresponde também à ação do espírito por intermédio de nós. Taylor se refere à distinção hegeliana entre o agir da comunidade e o agir do espírito, de tal sorte que haveria condiçôes de afirmar que certas açôes são propriamente açôes da comunidade e outras obras do espírito, como "espírito do mundo".

\section{Conclusão}

O tema da identidade política e cultural ganha, com o estudo tayloriano do agir humano, uma considerável contribuição. No geral, demonstra a possibilidade de o homem querer e erigir bens irredutivelmente sociais. Embora as sociedades democráticas liberais contemporâneas afirmem a tendência inversa de origem utilitarista, torna-se mais difícil sustentar a compreensão contrária ao status de bens irredutivelmente sociais. Alguns intérpretes de Taylor julgam, contudo, que falta ainda ao pensador um viés crítico. Em sua visão, Taylor sustenta uma perspectiva demasiado compreensiva da teoria ${ }^{18}$. Essa observação, à luz da exposição aqui exposta, parece insustentável. Taylor apresenta, com o auxílio da ontologia social hegeliana, com os conceitos que reelabora a partir das leituras de Wittgenstein e de Saussure, fortes argumentos

18 Beiner declara que "[...] me parece pertinente assinalar que Taylor não avança sua crítica das tendências individualista da vida moderna tão longe como poderíamos esperar" (BEINER, Ronald. Générosité herméneutique et critique sociale. In: LAFOREST, Guy; DE LARA, Philippe (Org.). Charles Taylor et l'interprétation de l'identité moderne. Quebéc/Paris: Les Presses de l'Université de Laval/ Le CERF, 1998, p. 146). 
para questionar o elemento crucial de sustentação da tese atomista, que consiste em afirmar que todos os bens públicos e sociais são decomponíveis.

Constata-se, igualmente, que a emblemática cartografia da identidade moderna recebe uma influência da noção hegeliana de um espaço comum compartilhado. Ela influencia Taylor na compreensão de que é possível pensar e razoavelmente coerente defender a ideia de um "eu" que é um "nós" que, ao mesmo tempo, é uma identidade. Com a assimilação do ponto de vista de que a totalidade apresenta o caráter transindividual e expressivista, Hegel reforça o argumento de que compreensóes comuns são indecomponíveis. Uma perspectiva essencialmente qualitativa da ação é defendida por Hegel que, igualmente, é assimilada por Taylor.

Finalmente, pode-se afirmar que Taylor parte da mesma estrutura argumentativa de seus adversários, ao erigir o seu questionamento aos bens sociais como somente convergentes. Os atomistas afirmam que as "totalidades" são inexoravelmente compostas de "partes" e que, por isso, na base de cada bem público ou social, se encontrariam sempre os indivíduos, os quais seriam, em última análise, responsáveis pela sua existência. No entanto, Taylor demonstra que há um erro colossal nesse entendimento, que distorce o modo como se dá a real mediação entre a totalidade e as partes, o qual gera uma série de problemas. Na sua avaliação, "[...] como doutrina filosófica, o bem-estarismo age como uma cortina que nos impede de ver nossa tarefa moral real e de identificar as verdadeiras alternativas. Ele pretende ter uma neutralidade que na realidade não goza." (TAYLOR, 2000b, p. 161)

O bem-estarismo promove isso, ao impedir a reflexão sobre que coisas efetivamente são bens, uma vez que subsume todo e qualquer bem a atos mentais de indivíduos, aos seus interesses e escolhas. Pensar que existam bens coletivos num sentido forte significa admitir que há alguma coisa acima dos atos mentais, das escolhas e açôes individuais, algo que não paira nas nuvens, como uma entidade estranha e mística, mas que se comporta como um referente tangível, que instrui e orienta as açôes individuais. Para Taylor, tal perspectiva aparece nas sociedades que têm um conjunto de significaçóes intersubjetivas, nas quais se forjam significaçôes comuns. Delas se pode dizer que possuem uma identidade, seja cultural, política ou nacional. Delas, igualmente, pode-se afirmar que não somente compartilham um determinado conjunto de significaçóes, visto que todo o mundo as possui, mas que há algo significativo comum, no sentido de que essas pessoas se sentem pertencendo a um mundo comum de referência. Nessas condições, uma verdadeira discussão moral seria possível, 
como a análise de que coisas podem ser consideradas bens segundo a teoria bem-estarista e seus oponentes. A perspectiva atomista impede essa discussão através do reducionismo tácito de que todos os bens têm de ser individuais e que qualquer outra concepção é incoerente. Contra tal intolerância Taylor se insurge com a defesa do debate sobre bens irredutivelmente sociais, debate que não simplesmente se apresenta como uma exigência de rigor intelectual, mas também um requisito de lucidez política e moral (TAYLOR, 2000b, p. 161).

HELFER, Inácio. Are Social Goods Always Convergent Goods?. Trans/Form/Ação, Marília, v. 35, n. 2, p. 163-186, Maio/Ago., 2012.

\begin{abstract}
A current strand of thought teaches that all collective goods are convergent goods. Its main exponents are the welfarist and utilitarian conceptions in the fields of economics and philosophy, respectively. This assumption presupposes that "social wholes" are inevitably composed of "parts", and that therefore the base of each public or social good is composed of individuals who would be ultimately responsible for its existence. Thus, public goods would be goods where the interests and choices of social actors converge. This essay shows that, first, according to Taylor's understanding, not all collective goods are convergent goods. Some social goods can be considered as irreducibly social goods, whose justification lies in reflection on their meaning. Second, it discusses the contribution that the Hegelian notion of ethics had on the formulation of this argument.
\end{abstract}

KEYWORDS: Convergent social goods. Irreducible social goods. Theory of action. Taylor. Hegel.

\title{
REFERÊNCIAS
}

ARAÚJO, Paulo Roberto Monteiro de. Charles Taylor: Para uma ética do reconhecimento. 2003. Tese (Doutorado) - UNICAMP, Campinas, São Paulo, 2003. Disponível em: http:// libdigi.unicamp.br/document/?code=vtls000302117. Acesso em: 02 nov. 2009.

BEINER, Ronald. Générosité herméneutique et critique sociale. In : LAFOREST, Guy; DE LARA, Philippe (Org.). Charles Taylor et l'interprétation de l'identité moderne. Quebécl Paris: Les Presses de L'Université de Laval/ Le CERF, 1998, p. 135-53.

BERTEN, A.; Da SILVEIRA, P.; POURTOIS, H. (Org.). Libéraux et communautariens. Paris: PUF, 1997.

HEGEL, G.W.F. Encyclopédie des sciences philosophiques. Texte intégral présenté, traduit et annoté par Bernard Bourgeois. Tomes III - édition de 1830. Paris: Vrin, 1988.

. Grundlinien der Philosophie des Rechts. Hrgs. von J. Hoffmeister. Hamburg: F.

Meiner, 1955. 
Vorlesungen über die Philosophie der Weltgeschichte. Band I: Die Vernunft in der Geschichte. Hrsg. von J. Hoffmeinster. Hambourg: F. Meiner, 1980.

HELFER, Inácio. Teoria da ação e mediações dialética em Hegel. Revista Eletrônica de Estudos Hegelianos, Rio de Janeiro, n. 14, v. 01, p. 04-20, jan./jun. 2011. Disponível em: http://www.hegelbrasil.org/reh_2011_1_art1.pdf. Acesso em: 30 maio 2012.

PÉLABAY, Janie. Charles Taylor, penseur de la pluralité. Laval et Paris: Les Presses de l'Université de Laval et L'Hartmattan, 2001.

SOUZA, Jessé José Freire. Charles Taylor e a relação entre cultura, democracia e reconhecimento social. In: OLIVEIRA, Nythamar Fernandes de; SOUZA, Draiton Gonzaga de (Org.). Justiça e politica: homenagem a Otfried Höffe. Porto Alegre: EDIPUCRS, 2003, p. 599-618.

TAYLOR, C. A importância de Herder. In: . Argumentos filosóficos. Trad. de Adail Ubirajara Sobral. São Paulo: Loyola, 2000a, p. 93-114.

. Argumentos filosóficos. Trad. de Adail Ubirajara Sobral. São Paulo: Loyola, 2000b.

. Bens irredutivelmente sociais. In: Argumentos filosóficos. Trad. de Adail Ubirajara Sobral. São Paulo: Loyola, 2000c, p. 143-161.

. Esprit et action dans la philosophie de Hegel. In: La liberté des modernes. Edição, trad. e apresentação de Philippe de Lara. Paris: PUF, 1997, p. 87-113.

. Hegel. Cambridge: Cambridge University Press, 1975.

. Hegel and Modern Society. Cambridge: Cambridge University Press, 1979.

. Hegel's Philosophy of Mind. In: . Human Agency and Language. Philosophical Papers I. Cambridge: Cambridge University Press, 1985, p. 77-94.

; DE LARA, Philippe. De l'anthropologie philosophique à la politique de la reconnaissance. Entretien de Philippe de Lara avec Charles Taylor. In: LAFOREST, Guy; DE LARA, Philippe (Org.). Charles Taylor et l'interprétation de l'identité moderne. Quebécl Paris: Les Presses de l'Université de Laval/ Le CERF, 1998. p. 351- 364.

. Philosophical arguments. Cambridge, Mass.: Harvard University Press, 1995.

Recebido em: 05.01.2012

Aceito em: 28.02.2012 